RECIST), khối u biến mất hoàn toàn kéo dài ít nhất 4 tuần và không xuất hiện tổn thương mới. Cụ thể, kết quả CT hàm mặt trước và sau tiêm cản quang tînh mạch cho kết luận không thấy khối, hay nốt trong các xoang cạnh mũi hai bên, không có tổn thương mô mềm, không có hình ảnh hạch lớn vùng cổ hai bên. Đối với kết quả chụp MRI hàm mặt cho thây vùng mô mềm vòm họng cũng như các tuyến mang tai tuyến dưới hàm, nhu mô não vùng hố sau, hình ảnh hạch hiện tại không thấy tổn thương nghi ngờ. Ngoài ra, các kết quả chụp CT lồng ngực, ổ bụng đánh giá tình trạng di căn đều cho thấy không phát hiện tổn thương. Đặc biệt, người bệnh ENB trong nghiên cứu thông qua các thăm dò cận lâm sàng cho thấy không có ảnh hưởng trên hệ tạo huyết cũng như ngoài hệ tạo huyết. Tại thời điểm hiện tại, hai người bệnh được ghi nhận không phát hiện các biến chứng cấp trong quá trình điều trị như viêm da, viêm niêm mạc miệng, khó nuốt hoặc khô miệng.

Do nghiên cứu chỉ được tiến hành mô tả cắt ngang, báo cáo chùm ca bệnh. Vì vậy, tại nghiên cứu này chưa thể cung cấp thông tin vể số năm sống sau điều trị của người bệnh. Tuy nhiên, nhóm nghiên cứu sẽ tiếp tục tục theo dõi và cập nhật khi có kết quả chính xác. Mặc dù những phát hiện trong nghiên cứu này không mang tính đại diện hoàn toàn, nhưng kết quả này chắc chắn góp phần cung cấp dữ liệu cơ bản ban đầu để nghiên cứu sâu hơn về bệnh ENB tại Bệnh viện $\mathrm{K}$ và các bệnh viện khác tại Việt Nam.

\section{KẾT LUẬN}

Triệu chứng lâm sàng chính của 02 người bệnh ENB là chảy máu và ngạt mũi bên trái, đau đầu, kéo dài lần lượt 1 tháng, 6 tháng trước khi nhập viện. Với phác đồ điều trị phẫu thuật kết hợp hóa xạ trị đồng thời hậu phẫu với liều $60 \mathrm{~Gy} / 30 \mathrm{fx}$ và hóa chất Cisplatin $100 \mathrm{mg} / \mathrm{m}^{2}$ đa chu kỳ 3 tuần. Kết quả điều trị cho thấy người bệnh bước đầu đáp ứng hoàn toàn và không có biến chứng trên hệ tạo huyết.

\section{TÀI LIÊU THAM KHẢO}

1. Olfactory neuroblastoma - PubMed. https://pubmed.ncbi.nlm.nih.gov/20596981/

2. Kuan EC, Nasser HB, Carey RM, et al. $A$ Population-Based Analysis of Nodal Metastases in Esthesioneuroblastomas of the Sinonasal Tract. Laryngoscope. 2019;129(5):1025-1029.

3. Dulguerov $\mathbf{P}, \quad$ Calcaterra Esthesioneuroblastoma: The UCLA experience 1970-1990. The Laryngoscope. 1992;102(8):843-849.

4. Kadish S, Goodman M, Wang CC. Olfactory neuroblastoma - A clinical analysis of 17 cases. Cancer. 1976;37(3):1571-1576.

5. Esthesioneuroblastoma: Results and Outcomes of a Single Institution's Experience - PubMed. Accessed March 12, 2021. https://pubmed.ncbi.nlm.nih.gov/19721769/

6. Broich G, Pagliari A, Ottaviani F. Esthesioneuroblastoma: A general review of the cases published since the discovery of the tumour in 1924 . 1924;17(2):683-706.

7. Dulguerov $\mathbf{P}$, Allal AS, Calcaterra TC. Esthesioneuroblastoma: a meta-analysis and review. 2001;2(11):683-690.

8. El Kababri M, Habrand JL, Valteau-Couanet D, Gaspar N, Dufour C, Oberlin 0 . Esthesioneuroblastoma in Children and Adolescent: Experience on 11 Cases with Literature Review. Journal of Pediatric Hematology/Oncology. 2014;36(2):91-95.

\title{
MộT SỐ YẾU TỐ LIÊN QUAN TỚI KIẾN THỨC TỰ CHĂM SÓC CỦA NGƯỜI BÊNH ĐÁI THÁO ĐƯỜNG TYPE 2 ĐIỀU TRI NGOẠI TRÚ TẠI BỆNH VIÊ̂N XÂY DỰNG TRONG THỜI KỲ COVID 19
}

\section{TÓM TẮT}

Mục tiêu: Mô tả thực trạng và các yếu tố liên quan đến kiến thức tự chăm sóc của ngưới bênh đái tháo đường type 2 điều trị ngoại trú tại Bệnh viện Xây

\footnotetext{
${ }^{1}$ Trường Đại học Y Hà Nội

²Bênh viện Xây dựng

Chịu trách nhiệm chính: Trần Thị Thanh Hương

Email: huongtran2008@gmail.com

Ngày nhận bài: 13.9.2021

Ngày phản biên khoa hoc: 10.11.2021

Ngày duyệt bài: 17.11.2021
}

\section{Trần Thị Thanh Hương ${ }^{1}$, Lê Việt Hạnh ${ }^{2}$} dựng thời kỳ Covid 19. Đối tượng và phương pháp nghiên cứu: Nghiễn cứu mô tả cắt ngang, đã được thực hiện với cỡ mẫu 300 người bệnh đái tháo đường type 2 đáp ứng tiêu chuẩn phỏng vấn bằng bộ câu hỏi chuẩn bi trước. Kết quả: Tỷ lể người bểnh chưa có kiến thức tốt về tự chăm sóc chiếm $40,3 \%$, với điểm trung bình của các nôi dung về tự chăm sóc đat 20,25 $\pm 3,49$ trên tổng điểm 30, trong đó chủ yếu là thiếu kiến thức về kiếm soát đường máu. Nghiên cứu của chúng tôi đã tìm ra mối liên quan giữa kiến thức với trình độ học vấn; thời gian mắc bệnh; thuốc điều trị đái tháo đường. Kết luận: Kiến thức tự chăm sóc của người bệnh đái tháo đường type 2 còn hạn chế. 
Tư khóa: Đái tháo đường type 2, tự chăm sóc, covid 19, kiến thức, thực hành.

\section{SUMMARY \\ THE SITUATION OF THE SITUATION OF SELF-CAREING KNOWLEDGE OF PEOPLE WITH TYPE 2 DIABETES OUTCOME TREATMENT AT CONSTRUCTION HOSPITAL IN THE TIME OF COVID 19}

Objective: Describe the current situation and factors related to self-care knowledge of type 2 diabetes patients treated as outpatients at the Construction Hospital during the Covid 19 period. Subjects and research methods: Research $A$ cross-sectional descriptive study was performed with a sample size of 300 patients with type 2 diabetes who met the interview criteria using a pre-prepared questionnaire. Results: The proportion of patients who do not have good knowledge of self-care accounted for $40.3 \%$, with the average score of the contents of self-care reaching $20.25 \pm 3.49$ out of a total score of 30 , in which the subject The weak point is the lack of knowledge about blood sugar control. Conclusion: It is necessary to combine many measures such as health education, strengthening supervision and patient clubs to support improving self-care knowledge for people with type 2 diabetes, especially in patients with type 2 diabetes Covid 19 period.

Keywords: Type 2 diabetes, self-care, covid 19, knowledge, practice.

\section{I. ĐẶT VẤN ĐỀ}

Đái tháo đường (ĐTĐ) là bệnh rối loạn chuyển hóa mạn tính mang tính chất xã hội. Bệnh đái tháo đường đã, đang và sẽ là gánh nặng cho nền kinh tế, xã hội của cả thế giới và mỗi quốc gia vào thế kỷ 21 . Theo thống kê của Liên đoàn đái tháo đường Quốc tế (IDF) năm 2019 cho thấy: Cứ 11 người trưởng thành (20-79 tuổi) lại có 1 người bị đái tháo đường. Như vậy, ước tính đến năm 2045 trên toàn thế giới sẽ có gần 700 triệu người mắc căn bệnh này [1]. Tại Việt Nam, vào năm 2015 đã có 3,5 triệu người mắc bệnh theo báo cáo của Hiệp hội đái tháo đường thế giới (IDF Diabetes Atlas) và con số này được dự báo sẽ tăng lên 6,1 triệu vào năm 2040. Biết cách tự chăm sóc bản thân là nội dung quan trọng đối với người mắc bệnh mạn tính, đặc biệt là bệnh đái tháo đường, trong đó kiến thức của người bệnh đóng vai trò quan trọng [2]

Đại dịch SARS-CoV-2 năm 2019 (Covid - 19) đã nổi lên như một trong những thách thức lớn nhất mà loài người phải đối mặt trong thời gian gần đây. Đại dịch này đã dẫn tới một số thay đổi trong cuộc sống cá nhân và xã hội; đối với người bệnh ĐTĐ vừa phải thay đổi thói quen sinh hoạt như tập thể dục, tuân thủ chế độ ăn, đến bệnh viện để khám định kỳ, lĩnh thuốc để tuân thủ các biện pháp phòng chống dịch SARS-CoV-2. Bệnh viện Xây dựng là Bệnh viện đa khoa hạng I với lượng người bệnh đái tháo đường đển khám khoảng 200 lượt một ngày. Tại các phòng khám hiện nay đang quản lý hơn 5000 người bệnh đái tháo đường type 2 điều trị ngoại trú. Câu hỏi đặt ra cho nhóm nghiên cứu là liệu kiến thức về tự chăm sóc của người bệnh đái tháo đường trong giai đoạn Covid-19 là như thế nào? Liệu kiến thức của người bênh có liên quan tới các yếu tô gì? Để có thể giúp xây dựng các chương trình can thiệp thích hợp, chúng tôi tiến hành nghiên cứu với mục tiêu "Mô tả một số yếu tố liên quan đên kiến thức tự chăm sóc của người bệnh đái tháo đường type 2 điều trị ngoại trú tại Bệnh viện Xây dựng trong thời kỳ Covid 19".

\section{II. ĐỐI TƯợNG VÀ PHƯƠNG PHÁP NGHIÊN CứU}

\section{1. Địa điểm, thời gian nghiên cứu:}

- Địa điểm nghiên cứu: Tại phòng khám Nội 2, Bệnh viện Xây dựng

- Thời gian nghiên cứu: Từ tháng 1/2021 đến $6 / 2021$

\section{2. Đối tượng nghiên cứu:}

*Tiêu chuẩn lứa chọn:

- Người bệnh ĐTÐ type 2 đang điều trị ngoại trú tại Bệnh viện Xây dựng

- Có khả năng tiếp nhận và trả lời các câu hỏi; đồng ý tham gia nghiên cứu.

*Tiêu chuân loại trừ:

- Người bệnh có các bệnh nặng khác ảnh hưởng đến khả năng giao tiếp hoặc chức năng nghe

- Người bệnh phải nhập viện điều trị nội trú.

- ĐTÐ típ 1, ĐTÐ khác có nguyên nhân

- Không hợp tác, không đồng ý tham gia nghiên cứu

2.3. Cỡ mẫu và phương pháp chọn mẫu:

*Cỡ mẫu: tính cỡ mẫu theo công thức cõ mẫu cho 1 tỷ lệ

$$
\boldsymbol{n}=\frac{z_{1-\frac{a}{2}}^{2} p(1-p)}{d^{2}}
$$

Trong đó: n: Là cõ̃ mẫu nghiên cứu tối thiểu; z: Là hệ số tin cậy ở mức xác suất $95 \%=1,96$

a: Độ tin cậy 95\%; d: Sai số ước tính d=0,04

p: Tỷ lệ NB ĐTÐ típ 2 có kiến thức, thực hành đúng về tự chăm sóc tại Việt Nam ước tính là 60 $\%$. Với các số liệu trên tính được $n=256$ người.

* Cách chọn mẫu: chọn mẫu thuận tiện 300 người bệnh đáp ứng đủ tiểu chuẩn chọn mẫu và được mời tham gia vào nghiên cứu

2.4. Thiết kế nghiên cứu: sử dụng phương pháp nghiên cứu mô tả cắt ngang

2.5. Công cụ thu thập số liệu: Bộ công cụ 
tự thiết kế gồm 4 phần: Thông tin chung về nhân khẩu học của đối tượng nghiên cứu, tiển sử bệnh, kiến thức, thực hành tự chăm sóc của người bệnh ĐTÐ type 2 gặp phải trong thời kỳ Covid - 19

2.6. Cách thức thu thập số liệu: Phỏng vấn trực tiếp các đối tượng theo tiêu chuẩn và đồng ý tham gia nghiên cứu

2.7. Phân tích số liệu: Sau khi thu thập số liệu được kiểm tra và làm sạch; sau đó, được nhập và̀ phân tích bằng phần mềm SPSS 22.0; Sử dụng thống kê mô tả để mô tả các tỷ lệ và các test thống kê thích hợp.

Tiêu chuẩn đánh giá kiến thức: Mỗi câu trả lời đúng được 1 điểm, mỗi câu trả lời sai/ không biết được 0 điểm, tổng số điểm tối đa là 30 điểm, thang đo đánh giá thực hành được phân thành 3 mức:

- Kiến thức kém khi trả lời đúng $\leq 50 \%$ tổng số điểm

- Kiến thức trung bình: trả lời đúng từ > 50\% đến $<70 \%$ tổng số điểm số điểm

- Kiến thức tốt: khi trả lời đúng $\geq 70 \%$ tổng

\section{KẾT QUẢ NGHIÊN CỨU}

Trong nghiên cứu của chúng tôi tuổi trung bình của đối tượng nghiên cứu là $66 \pm 8,54$ tuổi, phần lớn nằm trong nhóm tuổi từ 61 - 70 chiếm $44,7 \% \%$; thời gian mắc bệnh $\leq 5$ năm chiếm tỷ lệ cao nhất là $32,7 \%$. Trong số 300 ĐTNC người bệnh có trình độ học vấn trình độ Đại học/ Sau đại học chiếm $18,7 \%$. Tỷ lệ nữ là $57,3 \%$ cao hơn so với nam giới là $42,7 \%$. Phần lớn người bệnh đang điều trị hạ đường huyết bằng thuốc uống chiếm tỷ lệ cao $84,7 \%$ với tỷ lệ tái khám đúng hẹn trước khi có dịch Covid - 19 là $87 \%$.

Bảng 1 cho thấy Phần lớn người bệnh có kiến thức đúng chế độ ăn; tuy nhiên riêng kiến thức về bữa ăn phụ trước khi đi ñử thì chỉ có 30,3\% người bệnh trả lời đúng. Vẫn còn $22,3 \%$ người bệnh không biết phải dùng thuốc điều trị ĐTĐ ngay sau khi được chẩn đoán bệnh, chỉ có $26,3 \%$ người bệnh biết ảnh hưởng của hoạt động thể lực với nhu cầu dùng thuốc. Kiến thức tự theo dối đường máu còn hạn chế chỉ có $26,3 \%$ biết tần suất của việc tự theo dõi đường máu; 32\% ĐTNC biết không chỉ nhân viên mới có thể lập kế hoạch giúp người bệnh.

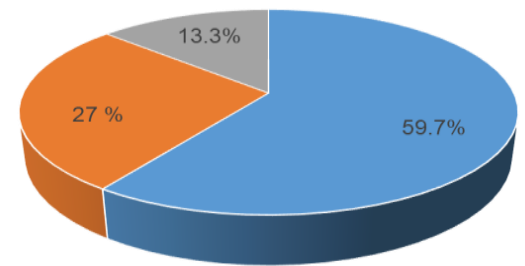

Biểu đồ 1. Phân bố kiến thức đúng nói chung của đôî tượng nghiên cứu

Tỷ lệ người bệnh có kiến thức tự chăm sóc đạt mức độ tốt chiếm tỷ lệ cao nhất là 59,7\%; tiếp đến kiến thức trung bình $27 \%$, kiến thức kém $13,3 \%$. Điểm trung bình của các nội dung về kiến thức tự chăm sóc đạt 20,25 $\pm 3,49$ trên tổng điểm 30 (Biểu đồ 1)

Bảng 1. Tỷ lệ ĐTNC có kiến thức đúng về tự theo dôi chăm sóc $(n=300)$

\begin{tabular}{|c|c|c|}
\hline Nội dung & $\mathbf{n}$ & Tỷ lệ \% \\
\hline \multicolumn{3}{|l|}{ Chế độ ăn } \\
\hline Nên ăn khi cảm thây đói, không cần ăn theo bữa. & 244 & 81,3 \\
\hline Biết những thực phẩm có chỉ số đường máu thấp. & 234 & 78,0 \\
\hline Hút thuốc lá có thể làm trầm trọng thêm bệnh đái tháo đường. & 251 & 83,7 \\
\hline Có bữa ăn phụ trước khi đi ngủ. & 91 & 30,3 \\
\hline \multicolumn{3}{|l|}{ Phòng biến chứng } \\
\hline Biết các biến chứng khi đường máu không được kiểm soát & 258 & 86,0 \\
\hline Đường máu cao gây ra các vấn đề về mắt bao gồm cả mù lòa. & 244 & 81,3 \\
\hline Các dấu hiệu của hạ đường huyết & 234 & 78,0 \\
\hline Các biện pháp bảo vệ bàn chân & 149 & 49,7 \\
\hline Biết các biểu hiện của biến chứng thần kinh & 131 & 43,7 \\
\hline \multicolumn{3}{|l|}{ Hoạt động thể lực } \\
\hline Biết về tấn suất hoạt động thể lực & 291 & 97,0 \\
\hline Biết về cường độ hoạt động thế lực & 275 & 91,7 \\
\hline Biết ảnh hưởng của hoạt động thể lực với nhu câu dùng thuốc. & 79 & 26,3 \\
\hline \multicolumn{3}{|l|}{ Kiểm soát đường máu } \\
\hline Không chỉ nhân viên y tế mới có thể kiểm tra lượng đường máu & 215 & 71,7 \\
\hline
\end{tabular}




\begin{tabular}{|c|c|c|}
\hline \multicolumn{3}{|l|}{ và huyết áp của người bệnh ĐTĐ. } \\
\hline Tần suất tư theo dõi đường máu & 79 & 26,3 \\
\hline Y nghĩa việc tự theo dõi đường máu & 279 & 93,0 \\
\hline $\begin{array}{l}\text { Kiếm soát đường máu bằng thay đổi lối sống thì không cân tự theo dõi } \\
\text { đường máu. }\end{array}$ & 161 & 53,7 \\
\hline $\begin{array}{l}\text { Xét nghiệm đường máu lúc đói được sử dụng để theo dõi kiểm soát } \\
\text { đường máu trong vòng 2-3 tháng. }\end{array}$ & 35 & 11,7 \\
\hline $\begin{array}{l}\text { Mức đường máu nên được theo dõi thường xuyên hơn khi tăng các } \\
\text { hoạt động thể lực. }\end{array}$ & 181 & 60,3 \\
\hline \multicolumn{3}{|l|}{ Theo dõi chăm sóc \& Phòng lây nhiễm Covid 19} \\
\hline Biết nguy cơ khi người bệnh ĐTĐ bị lây nhiếm Covid 19 & 275 & 91,7 \\
\hline Biết các biện pháp phòng lây nhiễm Covid - 19 & 230 & 76,7 \\
\hline Biết nội dung thông điệp "5K"c ủa Bộ Y Tễ & 278 & 92,7 \\
\hline NVYT mới giúp người bệnh đái tháo đường đạt được mục tiêu. & 96 & 32,0 \\
\hline Cần kiểm tra sức khỏe định kỳ ngay cả khi cảm thấy khỏe. & 267 & 89,0 \\
\hline Duy trì cân năng trong quản lý bênh đái tháo đường. & 194 & 64,7 \\
\hline \multicolumn{3}{|l|}{ Sử dụng thuốc } \\
\hline Việc sử dụng thuốc điều trị ĐTĐ duy trì suốt đời. & 277 & 92,3 \\
\hline Dùng thuốc điều trị ĐTĐ ngay cả khi cảm thấy khỏe & 270 & 90,0 \\
\hline Thời điểm dùng thuốc điều trị ĐTĐ & 233 & 77,7 \\
\hline $\begin{array}{l}\text { Chế độ ăn uống và tập thể dục không quan trọng bằng thuốc điều trị } \\
\text { ĐTĐ. }\end{array}$ & 253 & 84,3 \\
\hline
\end{tabular}

Bảng 2. Môi liên quan giữa kiến thức tự chăm sóc với yếu tố nhân khẩu học và tình trạng bệnh $(n=300)$

\begin{tabular}{|c|c|c|c|c|c|}
\hline \multirow{3}{*}{$\begin{array}{c}\text { Đặc điểm đối tượng } \\
\text { nghiên cứu }\end{array}$} & \multicolumn{3}{|c|}{ Kiến thức } & \multicolumn{2}{|c|}{ Hồi quy đơn biến } \\
\hline & Không đúng & Đúng & $\mathbf{p}$ & $\mathbf{O R}$ & $95 \% \mathrm{CI}$ \\
\hline & n (\%) & n (\%) & & & \\
\hline Nhóm tuối: $\leq 60$ & $30(44,8)$ & $37(55,2)$ & \multirow{3}{*}{$0,951^{a}$} & 1,1 & $0,6-2,1$ \\
\hline $61-70$ & $50(37,3)$ & $84(62,7)$ & & 0,8 & $0,4-1,4$ \\
\hline$>70$ & $41(41,4)$ & $58(58,6)$ & & $\frac{1}{1}$ & -2 \\
\hline Giới: & $46(35,9)$ & $82(64,1)$ & \multirow[b]{2}{*}{$0,18^{\mathrm{a}}$} & 0,7 & $0,4-1,1$ \\
\hline Nữ & $75(43,6)$ & $97(56,4)$ & & 1 & - \\
\hline Nghề nghiêp: Hưu & $90(39,1)$ & $140(60,9)$ & \multirow{3}{*}{$0,98^{\mathrm{a}}$} & 0,5 & $0,2-1,1$ \\
\hline CN/VC & $10(33,3)$ & $20(66,7)$ & & 0,4 & $0,1-1,2$ \\
\hline KD/LOTD & $21(52,5)$ & $19(47,5)$ & & 1 & - \\
\hline \multicolumn{6}{|c|}{ Trình đô hoc vấn } \\
\hline TH \& THCS & $60(63,8)$ & $34(36,2)$ & \multirow{4}{*}{$0,00^{a}$} & 10,5 & $4,4-24,9 * *$ \\
\hline PTTH & $39(41,9)$ & $54(58,1)$ & & 4,3 & $1,8-10,1 * *$ \\
\hline $\mathrm{TC} / \mathrm{CD}$ & $14(24,6)$ & $43(75,4)$ & & 1,9 & $0,747-5,108$ \\
\hline $\mathrm{ÐH} / \mathrm{Sau} \mathrm{ÐH}$ & $60(63,8)$ & $34(36,2)$ & & 1 & - \\
\hline \multicolumn{6}{|c|}{ Thời gian măc bênh } \\
\hline$\leq 5$ năm & $54(55,1)$ & $44(44,9)$ & \multirow{4}{*}{$0,00^{\mathrm{a}}$} & 4,7 & $2,3-9,6 * *$ \\
\hline $6-10$ năm & $35(51,5)$ & $33(48,5)$ & & 4,0 & $1,9-8,7 * *$ \\
\hline $11-15$ năm & $18(27,3)$ & $48(72,7)$ & & 1,4 & $0,6-3,2$ \\
\hline$>15$ năm & $14(20,6)$ & $54(79,4)$ & & 1 & - \\
\hline \multicolumn{6}{|c|}{ Tái khám đúng hen } \\
\hline Không & $108(41,3)$ & $153(58,6)$ & \multirow{2}{*}{$0,33^{\mathrm{a}}$} & 1,4 & $0,6-2,8$ \\
\hline Có & $13(33,3)$ & $26(66,7)$ & & $\frac{1}{1}$ & 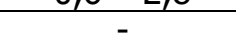 \\
\hline \multicolumn{6}{|c|}{ Tiền sử gia đình } \\
\hline Không & $45(36,9)$ & $77(63,1)$ & \multirow{2}{*}{$0,31^{\mathrm{a}}$} & 0,7 & $0,4-1,2$ \\
\hline Có & $76(42,7)$ & $102(57,3)$ & & 1 & \\
\hline \multicolumn{6}{|c|}{ Dùng thuốc đúng chỉ đinh } \\
\hline Đúng, không liên tục & $18(38,3)$ & $29(61,7)$ & \multirow[b]{2}{*}{$0,757^{\mathrm{a}}$} & 0,9 & $0,4-1,7$ \\
\hline Đúng, liên tục & $103(40,7)$ & $150(59,3)$ & & 1 & - \\
\hline
\end{tabular}




\begin{tabular}{|c|c|c|c|c|c|}
\hline \multicolumn{6}{|c|}{ Đang điều trị ĐTĐ } \\
\hline Thuốc uống & $109(42,9)$ & $145(57,1)$ & \multirow{3}{*}{$0,00^{b}$} & 3,1 & $1,3-6,9 * *$ \\
\hline Insulin & $4(80,0)$ & $1(20,0)$ & & 16,5 & $1,6-168,4^{*}$ \\
\hline Insulin và thuốc uống & $8(19,5)$ & $33(80,5)$ & & 1 & in 5 - \\
\hline \multicolumn{6}{|c|}{ Thực hành } \\
\hline Đạt & $80(61,1)$ & $51(38,9)$ & \multirow{2}{*}{$0,00^{b}$} & 0,2 & $0,1-0,3^{* *}$ \\
\hline Không đạt & $41(24,3)$ & $128(75,7)$ & & 1 & - \\
\hline
\end{tabular}

(a) test $\chi^{2} ;$ (b) Fisher's exact test; $\left(^{*}\right) p<0,05 ;(* *) p<0,01$

Sử dụng mô hình hồi quy logistic đơn biến với các biến độc lập là các biến đặc trưng về nhân khẩu học và tình trạng bệnh cho thấy những người bểnh có trình độ TH \& THCS, PTTH; có kiến thức khổng đúng cao gấp 10,5 lần (95\% CI: 4,4 $24,9) ; 4,3$ lần (95\% CI: 1,8 - 10,1) so với người bệnh có trình độ $\mathrm{DH} / \mathrm{sau} \mathrm{ÐH}$. Những người bệnh có thời gian mắc bênh $\leq 5$ năm; $6-10$ năm có kiến thức không đúng cao gấp 4,7 lần $(95 \% \mathrm{CI}$ : $2,3-9,6)$; 4 lân (95\% CI: 2,3 - 9,6) so với người bệnh có thời gian mắc bệnh > 15 năm. Nhóm người bệnh đang điều trị đái tháo đường bằng insulin, thuốc uống có kiến thức không đúng cao gấp 16,5 (95\% CI: 1,6 - 168,4); 3,1(95\% CI:1,3 - 6,9) so với người bệnh đang điêu trị bằng insulin kết hợp với thuốc uống. Đặc biệt, những người bệnh có kiến thức đúng có khả năng có thực thực hành đạt gấp 0,2 lần so với nhóm người bệnh có thực hành không đạt. Mối liên quan này có ý nghĩa thống kê $(p<0,05)$ (Bảng 2).

Bảng 3. Phân tích đa biến một số yếu tố liên quan đến tình trạng kiến thức và thực hành của đôî tượng nghiên cứu $(n=300)$

\begin{tabular}{|c|c|c|}
\hline \multirow{2}{*}{$\begin{array}{c}\text { Đă̆c điếm đối } \\
\text { tượng nghiên cứu }\end{array}$} & \multicolumn{2}{|c|}{ Kiến thức } \\
\hline \multicolumn{3}{|c|}{ Nhóm tuối } \\
\hline$\leq 60$ & $\mathbf{9 5 \%}$ CI \\
\hline $61-70$ & 0,934 & $0,555-0,424$ \\
\hline$>70$ & 1 & $0,482-1,832$ \\
\hline \multicolumn{3}{|c|}{ Trình độ học vấn } \\
\hline TH \& THCS & 9,7 & $3,8-24,6^{* *}$ \\
\hline PTTH & 4,5 & $1,7-11,2^{* *}$ \\
\hline TC/CĐ & 1,6 & $0,5-4,6$ \\
\hline ĐH/Sau ĐH & 1 & - \\
\hline \multicolumn{3}{|c|}{ Thời gian mắc bệnh } \\
\hline$\leq 5$ năm & 3,3 & $1,4-7,5^{* *}$ \\
\hline $6-10$ năm & 3,2 & $1,4-7,6^{* *}$ \\
\hline $11-15$ năm & 1,0 & $0,4-2,6$ \\
\hline$>15$ năm & 1 & - \\
\hline \multicolumn{3}{|c|}{ Đang điều trị ĐTÐ } \\
\hline Thuốc uống & 2,8 & $1,1-7,3^{*}$ \\
\hline Insulin & 47,6 & $3,2-694,5^{* *}$ \\
\hline Insulin và thuốc uống & 1 & - \\
\hline
\end{tabular}

$\left(^{*}\right) \mathrm{p}<0,05 ;\left(^{* *}\right) \mathrm{p}<0,01$
Bảng 3 cho thấy những yếu tố có mối liên quan có ý nghĩa thống kê với kiến thức tự chăm sóc là: trình độ học vấn, thời gian mắc bệnh, thuốc đang điều trị đái tháo đường $(p<0,05)$.

\section{BÀN LUÂ̂N}

Kết quả nghiên cứu của chúng tôi cho thấy trình độ học vấn, thời gian mắc bệnh, người bệnh đang dùng thuốc điều trị đái tháo đường có mối liên quan với kiến thức về tự chăm sóc. Kết quả này phù hợp với nghiên cứu của Tefera Kassahun [3] những người có trình độ THCS có kiến thức cao gấp 3,1(95\%: 1,03 - 9,3) lần so với người không biết chữ. Nhờ có kiến thức đúng về bệnh nên các người bệnh có trình độ $Đ H / s a u$ ĐH có kiến thức tự chăm sóc cao hơn người bệnh có trình độ từ PTTH trở xuống. Theo nghiên cứu Nguyễn Vũ Huyền Anh năm 2016 [4] cũng cho thấy trình độ học vấn càng cao thì mức độ kiến thức càng cao; nghiên cứu của Nguyễn Thị Thắm (2017) [5] nhóm có trình độ học vấn từ THPT trở lên có tỷ lệ kiến thức đạt chiếm $71,5 \%$ và cao gấp 6,09 lẩn so với nhóm có trình độ học vấn dưới THPT.

Kết quả nghiên cứu tại bảng 3 cho thấy sự khác biệt có ý nghĩa thống kê thời gian mắc bệnh với kiến thức chung tự chăm sóc. Kết quả này tương đồng với nghiên cứu của Nguyễn Vũ Huyền Anh [4]; Nguyển Thị Thắm [5]; Rahama [6]. Theo nghiên cứu của Tefera Kassahun với 325 người bệnh đái tháo đường típ 2 tại Ethiopia nhóm có thời gian mắc bệnh dưới 5 năm có kiến thức tự chăm sóc không đạt yêu cầu gấp 4,2 lần so với nhóm mắc bênh trên 10 năm [3]. Điêu này có thể do người bệnh có thời gian mắc bệnh càng lâu thì khả năng nhận thức về bệnh của người bệnh càng tăng cao, người bệnh sẽ tìm hiểu nhiểu hơn các thông tin về bệnh và tiếp cận nhiêu hơn với các chương trình giáo dục sức khỏe.

Nhóm người bệnh đang điều trị đái tháo đường bằng insulin, thuốc uống có kiến thức không đúng lần lượt cao gấp 16,5 lần; 3,1 lần so với người bệnh đang điều trị bằng insulin kết hợp với thuốc uống $(p<0,05)$. Kết quả nghiên cứu chúng tôi tương đồng với nghiên cứu của 
Haftom Niguse người bệnh dùng cả insulin và thuốc uống hạ đường huyết có kiến thức không đạt yêu câuu gấp 0,06 lân so với nhóm dùng insulin [7]. Điều này có thể lý giải việc sử dụng nhiều loại thuốc trong điều trị người bệnh sẽ nhận được nhiều thông tin tư vấn hướng dẫn sử dụng thuốc, kiểm soát đường huyết tốt hơn do đó kiến thức tự chăm sóc của người bệnh cũng tốt hơn.

Để đánh giá chính xác mức độ ảnh hưởng của các biến có liên quan đến kiến thức tự chăm sóc chúng tôi đã thực hiện kiểm định Logistic và mô hình hồi quy đa biến giúp chúng ta nhìn tổng quát và chính xác hơn mức độ ảnh hưởng của các biến độc lập đến biến mức độ kiến thức tự chăm sóc. Mô hình đã tìm ra các biến: trình độ học vấn, thời gian mắc bệnh, thuốc điêu trị đái tháo đường của người bệnh có liên quan đến kiến thức tự chăm sóc của người bệnh và có thể dự báo chính xác tới 68,3\% (Bảng 3)

\section{KẾT LUẬN}

Tỷ lệ người bệnh chưa có kiến thức tốt về tự chăm sóc chiếm $41,3 \%$, với điểm trung bình của các nội dung về tự chăm sóc đạt 20,25 \pm 3,49 trên tổng điểm 30, trong đó chủ yếu là thiếu kiến thức về kiểm soát đường máu. Trong giai đoạn Covid-19, kiến thức của người bệnh liên quản có ý nghĩa thống kê $(p<0,05)$ với trình độ học vấn OR = 10,6 (95\% CI: 4,5-25,0); thời gian mắc bệnh $\mathrm{OR}=4,7(95 \% \mathrm{CI}: 2,3-9,6)$; thuốc đang điêu trị là dạng uống/insulin với $\mathrm{OR}=3,1$ (95\% CI: 1,4-6,9).

\section{TÀI LIÊU THAM KHẢO}

1. Internation Diabetes Federation (2019). IDF Diabetes Atlas 9th edition 2019. Brussels, 212-215.

2. Federation International Diabetes IDF Clinical Practice Recommendations for managing Type 2 Diabetes in Primacy Care. Internation Diabetes Federation, 8, 1-43.

3. Kassahun T, Gesesew H, Mwanri L. (2016). Diabetes related knowledge, self-care behaviours and adherence to medications among diabetic patients in Southwest Ethiopia: a cross-sectional survey, BMC Endocr Disord, 16(1), 28.

4. Nguyễn Vũ Huyền Anh (2016), Đánh giá kiến thức tự chăm sóc của người bệnh đái tháo đường type 2 tai bênh viện đa khoa tỉnh Điên Biên năm 2016, Luận văn thạc sỹ điêu dưỡng, Đại Hoc Điều dương Nam Định.

5. Nguyễn Thị Thắm (2017), Thực trạng kiến thức và thực hành phòng biến chứng cưa người bênh đái tháo đường típ 2 điều trị ngoai trú tai Bểnh viện đa khoa Thành Phố Hà Tĩnh nằm 2017, Luận văn thạc sỹ điều dưỡng, Đại Hoc Điều dưỡng Nam Định, Nam Định.

6. Rahaman Kh.S, Majdzadeh R, Holakouie Naieni K. (2017). Knowledge, Attitude and Practices (KAP) Regarding Chronic Complications of Diabetes among Patients with Type 2 Diabetes. Int J Endocrinol Metab

7. Niguse H, Belay G, Fisseha G.(2019). Self-care related knowledge, attitude, practice and associated factors among patients with diabetes in Ayder Comprehensive Specialized Hospital, North Ethiopia. BMC research notes, 12(1), 1-7.

\section{NGHIÊN CỨU TÁC DỤNG CỦA NHĨ ẤP KÊTT HỢP PHƯƠNG PHÁP LUYÊ̂N THỞ DƯỠNG SINH NGUYỄN VĂN HƯỞNG VÀ TƯ VẤN TRONG ĐIỀU TRỊ CAI NGHIỆN THUỐC LÁ}

\section{TÓM TẮT}

Mục tiêu: Đánh giá tác dụng điều trị Hội chứng cai trong cai nghiện thuốc lá của phương pháp nhĩ áp kết hợp phương pháp luyện thở dưỡng sinh Nguyễn Văn Hưởng và tư vấn, theo dõi tác dụng không mong muốn của phương pháp can thiệp. Đối tượng và phương pháp: thử nghiệm lâm sàng tiến cứu, so sánh trước và sau điều trị. Đối tượng là 140 bệnh nhân. Liệu trình điều trị là 28 ngày. Khi hết liệu trình tiếp tục theo dõi quan sát bệnh nhân thêm 1 tháng,

*Bêenh viện Y học cổ truyền Trung ương

Chịu trách nhiệm chính: Trân Thái Hà

Email: phdtranthaiha@gmail.com

Ngày nhận bài: 13.9.2021

Ngày phản biện khoa học: 9.11 .2021

Ngày duyệt bài: 16.11.2021

\section{Trần Thái Hà*, Đào Hữu Minh*}

thêm 2 tháng để đánh giá hiệu quả của phương pháp can thiệp Kết quả: Cai nghiện thuốc lá đạt tỷ lệ $57.2 \%$ tốt, $16.4 \%$ khá và $26.4 \%$ không kết quả. Kết quả sau điêu trị 2 tháng không có sự thay đổi với tỉ lệ là $73.6 \%$ người không còn hút thuốc, sau điều trị 3 tháng tỉ lệ người không còn hút thuốc là $72,1 \%$. Kết luận: Nhî̉ áp kết hợp phương pháp luyện thở dưỡng sinh Nguyễn Văn Hưởng và tư vấn có tác dụng cai nghiện thuốc lá, cải thiện các triệu chứng của Hội chứng cai: thèm thuốc, İo lắng,căng thẳng, cáu gắt, giảm tập trung, tăng cân... và làm giảm hàm lượng CO trong hởi thở của bệnh nhân sau cai nghiện thuốc lá.

Ti̛ khóa: Cai nghiện thuốc lá, Hội chứng cai, nhĩ áp, luyện thở dưỡng sinh, tư vấn

\section{SUMMARY \\ STUDY THE EFFICIENCY OF SMOKING}

